\section{EXTRAORDINARY CASES OF POISONING.} To the Editor of THE LANCET.

SIR, - Will you kindly permit me, through the medium of your columns, to liy before your readers the following some what singular cases of poisoning which came under my care?

On the $19 \mathrm{th}$ of August, a family of ten persons residing in this neighbourbood, having at dinner partaken of a rabbit-pie, were all shortly afcerwards seized with diarrhcea and violent pains in the abdomen, which continued throughout the greater part of the night. Some astringent medicine having been ad. ministered, considerable relief was obtained. On the follow. ing morning, however, the precise cause of their illness not being suspected, several members of the family again partook of the remnant of the pie, reproducin'r the symptoms of the previous day in an alarmingly aggravated form, vomiting and violent cramps of the lower extremities being superadded.

Having been hastily summoned, I found on my arrival one of the patients in a state of collapse, pulseless, and insensible, and bathed in a cold, clammy perspiration. The others were also suffering more or less severely in proportion to the quantity of the poisonous food each person had eaten. Stimulants and opiates were promptly given, with immediate benefit, and under the treatment subsequently pursued, convalescence was soon established, though several days elapsed before they fully recovered from their exhausted and debilitated condition.

From inquiries instituted in the matter, it has been ascertained beyond doubt that these sudden and remarkable symptoms were attributable solely to the rabbit-pie, as each person who partook of it was similarly affected, and the symptoms recurred in every instance in those who again ate of it, whilst those who partook more sparingly of or avoided it escaped. The rabbits, and other materials composing the pie, it was proved were perfectly fresh and good, but were probably rendered unwholesome, though not unpalatable, by the process of cooking, having been baked beneath an impervious crust, which prevented the evaporation of the generated steam. It was afterwards permitted to stand for two or three days during very hot weather, which caused it to undergo a state of fermentation, as was observed from its peculiar appearance in the entire absence of jelly. Had the food been consumed when hot and freshly baked, or the confined steam freely permitted to escape by raising the paste, or otherwise affurding sufficient ventilation, it is probable that no injurious effects would have resulted ; at least such appears to me the only satisfactory explanation to account for the above remarkable symptoms. I am, Sir, your obedient servant,

Brandon, Sept. 1862. JoHN BuchenhaM, L.R.C.P. Ed.

\section{POTASH IN SCURVY.}

\section{To the Editor of The LANCE'T.}

SIR,-Dr. Aldridge, of Dublin, has communicated to me the copy of a letter he has addressed to THE LANCET, in which he complains-but in most courteous terms-that, in speaking of the hypothesis that scurvy is caused by deficiency of potash in my address to the British Medical Association, I have failed to notice his title to priority in promulgating that doctrine; and he refers to various published writings in evidence of his claim.

I am sorry I spoke of the authorship of the suggestion without having informed myself more fully in regard to it. As at present situated, I have not the means of consulting the works referred to by Dr. Aldridge, nor can I presume to pronounce an opinion on any question that may have arisen between him and Dr. Garrod on the subject; still I feel it due to Dr. Aldridge to express my regret that $I$ omitted, although, as he rightly supposes, unwittingly, to notice and do justice to his claim to priority in promulgating the doctrine in question.

I remain, Sir, your obedient servant,

Castleton of Braemar, Sept. 186?. W. SHARPEY, M.D.

\section{CASE OF RETAINED PLACENTA.}

To the Editor of THE LANCEr.

Sir, - Perhaps you may deem the following case of placenta retained for sixty-two days after the birth of the foetus wortby of publication :-

Mrs. carried in London on the 6 th of May last. Some weeks after this occurrence-in constquence of a constant discharge, which caused her much annoyance, and was attended with considerable constitutional disturbance-she was advised to come to Margate for the benefic of sea-air and sea bathing.

On the 7 th of July I was called in great haste to see her, and found her suffering under severe uterine pain. After hearing her history of the case, I satisfied myself by the usual examination that the placenta was still in the uterus; and having expressed my opinion and ordered what I thought necessary, I was in a few hours gratified by its expulsion.

My patient made a quick recovery, and was well pleased at the happy result. In size the placenta was as big as a very large flattened hen's egg.

I remain, Sir, your obedient servant, Hargate, Sept. 1:6?. GEO. YEATES HusTER, F.R.C.S.

\section{PERFORATING WOUND OF THE SCLEROTIC, CHOROID, AND RETINA.}

\section{To the Editor of $\mathrm{THE} \mathrm{LANCET}_{\mathrm{A}}$}

SIR, - With reference to the instructive case in the Middlesex Hospital under the care of $\mathrm{N} \mathrm{r}$. Soelberg Wells recordet in your journal of Aug. 23rd, permit me to mention, that while assistantsurgeon in England, an instance came under my observation, which, thongh not so interesting as the one above alluded to, is yet, perhaps, worthy of notice, as it also tends to prove that very serious injuries of the eyeball may be completely, or almost completely, recovered from. The case I now advert to is that of perforating wound of the sclerotic, choroid, and retina, and also of the vitreous humour, which injury was sustained by a miner while working in a coal-pit. The man stated that his own pick axe had entered the eyeball, owing (if my memory serves me) to the implement rebounding from the walls of the pit. The wound was a line or two behind the marrin of the cornea, and a bead or nodule, consisting of vitreous bumour, projected from it. An ansular flap of the sclerotica (and the subjacent tunics?) had been driven inwards by one of the sharp ends of the axe; but, as I suppose, its elasticity had caused it to resume nearly its former position. The treatment which was immediately had recourse to consisted in the administration of opium and mercury, and the continuous application of anodyne lotions. Iritis, as was anticipated, occurred, but in dne time it was subdued; the wound healed, and the eyesight was left very little, or not at all, impaired.

Edinburgh, Sept. 1862. I am, Sir, your obedient servant,

\section{VACCINATION IN WHOOPING-COUGH. To the Editor of THE LANCET.}

SiR,-During the spring of this year, pertussis prevailed epidemically amongst children in this parish and surrounding district. As several of them had not been vaccinated, I availed myself of the opportunity of trying the effects of vaccination as a remedy for that disease.

I selected ten cases of uncomplicated whooping cough. A few days after its employment, I found the symptoms greatly mitigated-the severity of the congh was much lessened, and the intervals between the paroxysms were lengthened. In all the cases the disease progressed favourably, and was shorter in duration than it usually is by the ordinary method of treatment

The ares of the children varied from three months to two years, and the time of emlloying it was about the third week of the disease. No medicine was used in any of the cases, with the exception of gentle laxatives. Vaccination as a remedy for whooping cough was first proposed in Germany, and is not only practised in that country, but also in America.

About thirty years ago it was introrlucer into this country, and although favourably spoken of at the time, yet it was allowed to fall into disuse. Whether children so treated will enjoy an immunity from small-pox, I am unable to say; but I may mention that in three of the cases in which I attempted to revaccinate after the removal of the ciiseuse, the virus had no effect.

I am, Sir, your obedient servant, R. C. Ricseet, L.R.C.S.E.

Nerrmachar, Aberdecnshire, Sept. 1862

New Sanitaricu for Exglish Soldiers ix Troia.The estabishment rf a sanitarium for European soldiers on the island of Callyouls. of the Tenasserm coist, has heen commenced. Capiain Fraser furnished the plan and details of the bulding. 